\title{
Asymmetric Volatility Relevance in Risk Management: An Empirical Analysis using Stock Index Futures
}

\author{
Guillermo Benavides ${ }^{1}$ - Banco de México², México
}

The objective of this research work is to show the relevance of asymmetries in estimating volatility. The methodology consists in the application of ARCH-type models and implied volatilities of options (IV) to estimate Value-at-Risk (VaR). These for a portfolio of stock index futures for various time horizons. The empirical analysis is carried out for the futures contracts for the Standard and Poors 500 and Mexican Stock Exchange Indices. According to the results, the IV model is superior in terms of precision compared to the ARCH-type models. It is recommended to use the relevant statistical gains when asymmetries are included with respect to when asymmetries are not used. The referred gains range from 4 to 150 basis points of minimum capital risk requirements. The originality of the present work consists of showing the importance of considering the asymmetric effects with IV and ARCH-type models in volatility forecasts within risk management analysis. It is concluded that the methodology means gains in monetary terms.

JEL Classification: C15, C22, C53, E31, E37.

Keywords: Asymmetric volatility, backtesting, GARCH, TARCH, implied volatility, stock index futures, Value at Risk, Mexico.

\section{Relevancia de la Volatilidad Asimétrica en la Administración de Riesgos: Un Análisis Empírico Utilizando Futuros de Índices Accionarios}

El objetivo del presente documento es considerar la relevancia de las asimetrías en la estimación de la volatilidad. La metodología consiste en estimar modelos de ARCH-tipo y volatilidades implícitas de opciones (IV) para el Valor-en-Rriesgo (VaR). Lo anterior para una cartera de futuros de índices bursátiles para varios horizontes temporales. El análisis empírico se realiza para los contratos de futuros para los Índices Standard and Poors 500 y el de la Bolsa Mexicana de Valores. De acuerdo con los resultados, el modelo IV es superior en términos de precisión en comparación con los modelos de ARCH-tipo. Se recomienda considerar las ganancias estadísticas relevantes cuando se incluyen asimetrías con respecto a cuando no se usan asimetrías. Las referidas ganancias van de 4 alrededor de 150 puntos base de requerimiento mínimo de capital en riesgo. La presente investigación es original, ya que, documenta la importancia de tener en cuenta los efectos asimétricos con IV y ARCH-tipo en los pronósticos de volatilidad en el análisis de gestión de riesgos. Se concluye que la metodología permite ganancias en términos monetarios.

Clasificación JEL: C15, C22, C53, E31, E37.

Palabras clave: Volatilidad asimétrica, GARCH, TARCH, volatilidad implícita, futuros índices accionarios, Valor en Riesgo, México.

1 Dirección de Medición Económica, Banco de México. Mailing address: Dr. Guillermo Benavides, Av. Cinco de Mayo \# 2, Col. Centro, Ciudad de México, CP. 06059, México. Email: gbenavid@banxico.org.mx

2 The views expressed in this paper are those of the author only and do not necessarily reflect those of Banco de México or its staff. I want to thank Aldo Heffner, seminar participants at Banco de México, UVM, FIMEF and anonymous referees for valuable comments. All remaining errors are my own.

* No source of funding for research development 


\section{Introduction}

Measuring financial risks is the backbone of risk management and portfolio investments decisions. A well-known financial risk measure is the volatility of assets prices, as it allows the risk manager to assess potential risks associated with portfolio investments. Forecasts of price returns volatilities is perhaps the most used analytical toolkit for measuring financial risk, since are useful to make contemporaneous decisions based on expectations about the future level of prices. It is known in theory about the link between futures prices and expected future spot price. An advantage of using futures prices instead of spot prices, is that the former usually contain relevant information about the representative trader's future spot price expectation (Hull: 2019). Given the previously mentioned forward-looking component embedded in futures prices, it is relevant to consider these derivative instruments for financial decision making. Indeed, the price return volatility of futures prices has been used for risk management research in previous works (Bollerslev, Chou and Kroner: 1992, Engle: 2003).

In the finance literature, volatility is seen as a risk variable, which captures all the uncertainty surrounding that financial variable. It is well-known that in the presence of asymmetric volatility it is important to adjust risk models to avoid possible under (over) quantification of risks. An unintended risk missestimation is undesirable for a financial institution involved in quantifying risks, given the potential costs associated with not being at an optimal risk quantification value (Brooks et. al.: 2000). On the one hand, handling an extreme event might be particularly costly to a firm with insufficient capital reserves, if its risk was underestimated in the first place. On the other hand, an overestimated risk may reserve excessive capital compared to its optimal level, which cause the manager to have more than is required (capital reserves), with a high opportunity cost of other uses of capital.

In this study, we aim to assess whether volatility is asymmetric and determine to what extent may impact stock market dynamics. The objective is to quantify if there are any statistically significant differences between taking and not taking into account possible asymmetric effects in volatility within a VaR framework for stock indices. The methodology involves backtesting techniques to validate $\mathrm{VaR}$ models that are relevant for risk management (Kupiec: 1995, Jorion: 2001). The volatility measures used are GARCH, TARCH and option implied volatility (IV). These last two are able to capture volatility asymmetries. The ARCH-types are considered a 'backward-looking' forecast estimation methods, whilst the IV is considered a 'forward-looking' one. A contribution of the present research analysis is the combination of both types of techniques from a VaR perspective. For the purpose of the present study, asymmetric volatility is defined as the difference in the volatility level given positive or negative returns. In other words, the volatility may be higher when the returns are negative (or in some cases when they are positive).

The goal of the present research paper is twofold. First, provide optimal risk measures in order to avoid misestimation of risks, underlying the need to adjust for any volatility asymmetries applying statistical methods. In doing that, we need to prevent unnecessary financial costs related to a non-optimal risk measure. By adjusting the model for volatility asymmetries, it is expected that a risk measure with higher accuracy can be obtained. Second, we propose a novel approach to compare two different types of asymmetric volatility forecasts: one that is backward-looking (ARCH-type) and 
one that is forward-looking (option-implied), within a VaR framework. Most research papers use one or the other measure, but they do not compare them in terms of statistical performance in a VaR paradigm (Giot: 2005, Chkili et. al.: 2014). We here assess each one of them and various combinations, including statistical inference. We start comparing volatility symmetries vs. asymmetries and also backward- vs. forward-looking within a VaR model. The comparison of the results for two different types of asymmetric volatility methodologies could give light about any qualitative differences that should be accounted for when deciding on VaR estimations.

The results show that asymmetric models provide more accurate VaR estimations. Among these the forward-looking forecast model is superior when compared to the backward-looking one. Based on these results, it is recommended to apply asymmetric IV volatility models, with VaR in particular, to perform risk management analysis. We argue that the present paper adds relevant information to the academic literature on of volatility forecast methodologies since our findings provide evidence about the accuracy gains of using asymmetric volatility models in the risk management sector. Also, the results can be useful for those involved in the risk management industry, i.e. portfolio-risk managers, to have better knowledge about superior (and close to optimal) estimation procedures.

The layout of this paper is as follows. The literature review is presented in Section II. Symmetric and asymmetric models are explained in Section III. Data is described in detail in Sections IV and V, respectively. The results of four volatility models are discussed in Section VI. Section VII concludes.

\section{Literature Review}

It is well documented that non-linear Autoregressive Conditional Heteroskedasticity type models (ARCH-type models) can provide accurate in-sample estimates of time-varying price volatility. These type of volatility forecast models are also considered backward-looking, i.e. the estimates are obtained based on past time series data. ${ }^{3}$ See for example, Engle (1982), Taylor (1986), Bollerslev, Chou and Kroner (1992), Wei and Leuthold (1998), Engle (2002), among many others. ${ }^{4}$ However, the out-of-sample forecasting accuracy of this type of non-linear models is, in some cases, questionable (see Park and Tomek: 1989, Schroeder et. al.: 1993, Manfredo et. al.: 2001, Benavides: 2006, 2009, Pong et. al.: 2003). 5

In addition, there is a related literature of the implications of non-linear dynamics of volatility forecasts for financial risk management (Hsieh: 1993). In light of this, some researchers have extended previous work on the application of time-varying volatility models, specifically ARCH-type models, and IV in VaR estimations (Brooks, Clare and Persand: 2000; Manfredo et. al.: 2001; Engle:

\footnotetext{
3 The volatility forecast that it is considered here is the conditional volatility of a financial asset, which is estimated from an econometric model assuming a standard distribution for the estimated parameters.

4 For an excellent survey about applications of ARCH-type models in finance the interested reader can refer to Bollerslev, Chou and Kroner (1992).

${ }^{5}$ All of them found that the explanatory power of these out-of-the-sample forecasts is relatively low. In particular, Pong et al. (2003) find that option implied volatility forecasts performed at least as well as forecasts from Autoregressive Fractional Integrated Moving Average Models (ARFIMA) for time horizons of one and three months. These were superior forecasts to those from ARCH-type models.
} 
2003; Giot: 2005; among others). IV estimations are considered forward-looking since they are implied by derivative contracts (prices) and it is believed that these increase the performance of the volatility forecasts compared with the ARCH-type. Most of previously mentioned findings improved risk management applications using $\mathrm{VaR}$, by proving to be more accurate in terms of quantifying risk. Although, there are several research papers that use these types of models for financial time series, there is, to the best of our knowledge, no research that carries out a rigorous comparison of volatility asymmetries using both ARCH-type (backward-looking) and option-implied (forward-looking) volatility within a risk management VaR perspective. Furthermore, there are no research documents in which there is an empirical comparison between risk properties of two stock indices, one from an advanced economy (the SP500 stock index) and one from an emerging economy market (the IPC Mexican stock index), in which volatility asymmetries are accounted for.

Among the main objectives of the present research document is to extend previous research in two dimensions. One is that Minimum Capital Risk Requirements (MCRR) are estimated for futures contracts of the S\&P 500 and the IPC. These following Basel II and III accords. The other one is a formal analysis of empirical applications of ARCH-type models and option implied volatilities, which both include asymmetric volatility effects. Furthermore, rigorous statistical accuracy tests for estimating VaR are carried out between ARCH-type models vs. IV following Kupiec (1995) backtesting tests. These results could be of interest of agents involved in risk management decisions related to stock index forecasts, i.e. private bankers, financial analysts, policy makers, academic researchers, among others.

\section{The Models}

\subsection{Volatility Models}

\subsubsection{ARCH-Type (GARCH-Symmetric) Specification}

The volatility of the time series under analysis is estimated with historical data. A well-known model within the family of ARCH-type models is the univariate Generalized Autoregressive Conditional Heteroscedasticity, $\operatorname{GARCH}(p, q)$ model. This is an extension of the $\operatorname{ARCH}(q)$ model, in the sense that the ARCH model is nested in the GARCH model. The $\operatorname{GARCH}(p, q)$ model is estimated by applying the standard procedure as explained in Bollerslev (1986) and Taylor (1986). 6 The parameters are estimated using a maximum likelihood methodology applying the Marquardt algorithm. ${ }^{7}$ These models are standard in the academic literature.

${ }^{6}$ The ARCH-type models presented in the present research paper were estimated using Eviews computer.

7 This algorithm modifies the Gauss-Newton algorithm by adding a correction matrix to the Hessian approximation. This allows handling numerical problems when the outer products are near singular, thus increasing the chance of improving the convergence of the parameters. 


\subsubsection{Threshold GARCH (GARCH-Asymmetric) Model}

Another model used in this paper is the Threshold GARCH model, also known as TARCH. It was postulated by Glosten, Jaganathan, and Runkle (1993) and Zakoïan (1994). Compared with the $\operatorname{GARCH}(p, q)$ model, the specification of the TARCH model involves an additional term in the variance equation, that captures the asymmetric dynamics of the price-returns:

$$
\sigma_{t}^{2}=\omega+\sum_{i=1}^{q} \alpha_{i} \varepsilon_{t-i}^{2}+\sum_{j=1}^{p} \beta_{j} \sigma_{t-j}^{2}+\sum_{k=1}^{r} \delta_{k} \varepsilon_{t-k}^{2} I_{t-k}^{\prime}
$$

where $I_{t}^{\prime}=1$ if $\varepsilon_{t}<0$ and 0 otherwise. $\varepsilon_{t}$ represents an innovation (error term). The intuition for this model is that bad news $\varepsilon_{t}<0$ will have a different impact on the conditional variance compared to good news $\varepsilon_{t}>0 .{ }^{8}$ In case of good news, the impact is on $\alpha_{i}$ for bad news the impact is on $\alpha_{i}+\delta_{i}$. If $\delta_{i}$ $>0$ and is statistically significant, there will be a higher increase in volatility driven by bad news. If $\delta_{i}$ $\neq 0$, then the news impact is asymmetric. This model is normally used for estimating stock price volatility considering the leverage effect on stocks. ${ }^{9}$ For the case of the stock-index futures, the asymmetric TARCH model is applied. Considering that the assumption of normality of the residuals stated above usually does not hold, the Bollerslev and Wooldridge (1992) methodology is used to estimate consistent standard errors. The estimators under the previously mentioned procedure are then statistically robust and obtained from Quasi-Maximum Likelihood Estimation. Thus, the coefficients are robust even if the normality assumption is not met by the data.

\subsubsection{Option-Implied Volatility (IV) Model}

In this research paper, option implied volatilities provided by the Chicago Mercantile Exchange and MexDer are used. These are the VIX (option implied volatility index), which is an implied volatility for thirty-days ahead, and the VIMEX, which is the equivalent volatility index for the Mexican stock index for nine-days ahead. The latter has had a consistent methodology through time. The optionimplied volatility of an underlying asset is the market's forecast of its volatility, and this is obtained with the options written on that underlying asset (Hull: 2019). To calculate an option implied volatility of an asset, an option valuation model is needed as well as the inputs for that model, such as the risk-free rate of interest, time to maturity, price of the underlying asset, the exercise price, and the price of the option. To obtain the relevant volatility indices a standard methodology is applied, in which there is an estimation of a Risk-Neutral Density (RND). The implied standard deviation of that RND is then used as the IV. This volatility index gives an indication of the uncertainty of the underlying asset. Even in the term of maturity may be different for different assets, these are still comparable given that is a 'forward-looking' perception of the economic agents. Furthermore, the application of a RND methodology makes it consistent even if it is considered in- and out-of-the-

\footnotetext{
${ }^{8}$ Good news refers to news that increase financial assets returns. Bad news is the opposite.

9 The leverage effect on stocks refers to asymmetric volatility considering that a bear market sentiment has higher price volatility when compared with a bull market sentiment. In a bear market higher uncertainty about the cash flow stream could cause the stock price to decrease and the company increases its leverage ratio, which is undesirable (Brooks: 2013).
} 
money options. Since the whole implicit distribution of the asset price is estimated, there is no bias in terms of the moneyness of the options. For that RND both calls and puts are included to avoid possible clientele effects.

\subsection{The Value-at-Risk (VaR) Model}

The Value-at-Risk or VaR model is a useful measure of risk. ${ }^{10}$ It was developed in the early 1990s by the JP Morgan Corporation. According to Jorion (2001) 'VaR summarizes the expected maximum loss over a target horizon with a given confidence interval.' Even though it is a statistical figure, most of the times VaR estimates are presented in monetary terms. The intuition is to have an estimate of the potential change in the value of a financial asset resulting from systemic market changes over a specified time horizon. It is also normally used to obtain the probability of losses for a financial portfolio of futures contracts. Assuming normality, the VaR estimate is relatively easy to obtain from GARCH models. For example, for a one trading day 95\% confidence interval VaR, the estimated GARCH standard deviation (for the next day) is multiplied by \pm 1.645 . If the standard deviation forecast is, say, 0.0065 , the VaR is approximately $1.07 \%$, looking at the positive tail of the distribution. To interpret this result, it could be said that an investor can be $95 \%$ sure that she will not lose more than $1.07 \%$ of asset or portfolio value in that specific day. However, a problem with the parametric approach is that if the observed asset returns depart significantly from a normal distribution the applied statistical model may be incorrect to use (Dowd: 1998).

For time horizons of more than one trading day (ten, and twenty trading days), the bootstrapping methodology of Efron (1982) is applied. ${ }^{11}$ The fact that the returns of the series are non-normally distributed motivates the use of a non-parametric procedure such as bootstrapping. The procedure used in Hsieh (1993) and Brooks, Clare and Persand (2000) is considered here. In the latter, they empirically test the performance of that VaR model for futures contracts traded in the London International Financial Futures Exchange (LIFFE). ${ }^{12} \mathrm{~A}$ similar paradigm is applied here for stock-indexed futures contracts. Thus, a hypothetical portfolio of stock-indexed futures is considered and MCRRs are estimated. ${ }^{13}$ These estimated MCRRs values for the stock index futures portfolio are compared to the observed (historical) inflation. This analysis allows the evaluation of how accurate the ARCH-type models are in terms of estimating MCRRs for stock-indexed futures. Another objective

\footnotetext{
10 Value at Risk is normally abbreviated as VaR. The lower case ' $a$ ' letter differentiates this abbreviation to that of Vector Autoregressive Models, which are usually abbreviated as VAR (with a capital $A$ ).

11 The bootstrap is a resampling method for inferring the distribution of a statistic, which is derived by the data in the population sample. This is normally estimated by simulations. It is said to be a nonparametric method given that it does not draw repeated samples from well-known statistical distributions. Alternatively, a Monte Carlo simulation draws repeated samples from assumed statistical distributions. In this research project the bootstrap methodology was implemented using Eviews.

12 These futures contracts were the FTSE-100 stock index futures contract, the Short Sterling contract and the Gilt contract. 13 In finance textbooks it is common to see that the theoretical futures (forward) price is expressed in continuous time, (Hull: 2019): $F_{0}=S_{0} e^{r T}$. Where $F_{0}$ is the current futures (or forward) price, $S_{0}$ is the current spot price, $e$ equals the $e(\cdot)$ function, $r$ is the risk-less rate of interest per annum expressed with continuous compounding and $T$ is the time to maturity in years. For the previous formula it is assumed that the underlying asset pays no income. For the research purposes of this project $F_{0}$ equals the observed stock-index futures price as reported by CME and MEXDER (in discrete time) and $S_{0}$ equals the observed stock index spot price, taken from a Bloomberg terminal.
} 
is to analyze the performance of these in terms of how accurate they are for providing an upper threshold for the stock index, i.e. the statistical chances that the stock index will be high enough to be outside the upper (positive) confidence interval. It should be point out that the series for the bootstrap are the futures prices. The volatility series (VIX and VIMEX) are not bootstrapped since the objective is to have the simulated distribution of the objective series (futures prices).

In order to calculate an appropriate VaR estimate it is necessary to find out the maximum loss that a position might have during the life of the futures contract. In other words, by replicating via the simulations (bootstrapping) the daily values of a long futures position it is possible to obtain the possible loss during the sample period. This will be given by the lowest replicated value. The same reasoning applies for a short position. But in that case the highest possible loss will be given by the highest replicated value. ${ }^{14}$ Following Brooks, Clare and Persand (2000) and Brooks (2013) the formula is as follows. The maximum loss $(L)$ is given by

$$
L=\left(P_{0}-P_{1}\right) * \text { Number of contracts }
$$

where $P_{0}$ represents the price at which the contract is initially bought or sold; and $P_{1}$ is the lowest (highest) simulated price for a long (short) position, respectively, over the holding period. Without loss of generality it is possible to assume that the number of contracts held is one. Algebraically:

$$
\frac{L}{P_{0}}=\left(1-\frac{P_{1}}{P_{0}}\right) .
$$

Given that $P_{0}$ is a constant, the distribution of $L$ will depend on the distribution of $P_{1}$. It is reasonable to assume that prices are lognormally distributed (Hsieh: 1993), i.e. the log of the ratios of the prices are normally distributed. However, this assumption is not considered here given that empirical distributions of the series under study are not normal. However, the log of the ratios of the prices is transformed into a standard normal distribution following J.P. Morgan Risk-Metrics (1996) methodology. This is done by matching the moments of the log of the ratios of the prices' distribution to a distribution from a set of possible ones known (Johnson: 1949). Following Johnson (1949) a standard normal variable can be constructed by subtracting the mean from the log returns and then dividing it by the standard deviation of the series,

$$
\frac{\ln \left(\frac{P_{1}}{P_{0}}\right)-\mu}{\sigma}
$$

The expression above is approximately normally distributed. It is known that the $5 \%$ lower (upper) tail critical value is $-1.645(+1.645)$.

\footnotetext{
${ }^{14}$ As it is well known in futures market payoffs that decreases in futures prices mean losses for long positions and increases in futures prices mean losses for short positions.
} 
From Equation 6 the following can be expressed as

$$
\frac{L}{\overline{P_{0}}}=1-\exp [-1.645 \sigma+\mu]
$$

when the maximum loss for the long position is obtained. For the case of finding the maximum possible loss for the short position the following formula applies:

$$
\frac{L}{P_{0}}=\exp [1.645 \sigma+\mu]-1
$$

The MCRRs of the short position can be interpreted as an upper threshold for the stock index. These considered a 90\% confidence interval. By the same reasoning the MCRRs of the long position can be interpreted as a lower threshold for the stock index, with the same confidence level. The simulations were performed in the following way. The GARCH and TARCH models were estimated with the bootstrap using the standardized residuals from the whole sample (instead of residuals taken from a normal distribution as was written in Equation 1). The stock index variable was simulated, for the relevant time horizon (10 and 30 trading days) with 10,000 replications. The formula used was $Y_{t+1}=Y_{t} e^{r T}$ (where $Y$ is the futures price, $r T$ are the underlying asset's returns for time $T$, from an ARCH-type (GARCH, TARCH) model and the rest of the notation is the same as specified above). From the futures price indices simulations, the maximum and minimum values were taken in order to have the MCRRs for the short and long positions respectively.

\section{Data}

\subsection{Data Sources}

It is known that the US capital market is a relatively large and liquid market. In contrast the Mexican capital market is relatively smaller and less liquid. These different types of markets may give light about differences between capital markets (investments) between developed and developing stock markets within a VaR framework. In the present research project, stock index volatility for both the US Standard \& Poor's 500 Index (S\&P500) and Mexico 'Índice Nacional de Precios y Cotizaciones' (IPC) are analyzed using their respective daily stock futures indices. The methodology is carried out for futures prices of both stock indices. The data consists of daily spot and futures closing prices of the IPC and S\&P indices obtained from MEXDER and CME respectively. ${ }^{15}$ The sample period under analysis consists of more than two years of daily data for a time frame from 3rd January 2016 to 30th December 2019. The sample size consists of 889 daily observations. The sample period was chosen

\footnotetext{
15 The MEXDER web page is http://www.mexder.com.mx/MEX/paginaprincipal.html The CME webpage is https://www.cmegroup.com/trading/equity-index/us-index/sandp-500.html
} 
considering the most recent data available in Bloomberg, which for IPC futures is from January 2016. The sample size of 889 observations is considered large enough for the estimation task at hand. These types of derivative contracts have daily trading and daily data is commonly publicly available. Given that the time horizon for these simulations is relatively short (up to one month ahead) there is no need for a larger sample size. The futures contracts for the Mexican IPC have delivery dates for up one year and a half ahead. The periodicity of the maturities of the contracts is four times within one year and the delivery months are March, June September and December.

\section{Descriptive Statistics}

This section presents the descriptive statistics for the daily (observed) volatilities of the IPC and S\&P500 spot and futures returns. The volatility forecast from the models is also presented. Prior to fitting the GARCH and TARCH models, an ARCH-effects test was conducted for the series under analysis. This can be applied if the series under study are stationary. For these series it is the case since these were transformed with first differenced logs. ARCH-LM tests are needed to see if the time series are appropriate for the models (Brooks: 2013). The test was conducted following the procedure of Engle (1982). ${ }^{16}$ According to the results both series under study have ARCH effects. Under the null of homoscedasticity in the errors the $F$-statistics were 8.04 for the spot and 4.00 for the futures prices of the IPC (the critical value is 2.21 for 5 restrictions, 877 degrees of freedom). Both statistics clearly reject the null in favour of heteroscedasticity on those errors. For the S\&P 500 the results were qualitatively similar, indicating heteroscedasticity on those errors dynamics $(F-$ statistics were 21.75 for the spot and 21.79 for the futures prices of the S\&P500). Therefore, it is consistent to apply ARCH-type models to the data.

According to Zivot (2009) it is possible to test for asymmetric effects analyzing the returns of the sample series. If $r_{t}^{2}$ and $r_{t-1}$ have a negative correlation coefficient (statistically different from zero) then there are asymmetric effects (also known as 'leverage effects'). For the series under study these are -0.0634 and -0.0989 for the spot and futures respectively IPC series and -0.1570 and 0.2089 for the spot and futures respectively S\&P500 series. ${ }^{17}$ Given that there are asymmetric effects the TARCH model explained above will be applied in the following estimations. Tables 1 and 2 show the parsimonious specifications GARCH $(1,1)$ and TARCH $(1,1)$ for the IPC and S\&P500, respectively. These models were chosen according to results obtained from information criteria (Akaike Information Criterion and Schwarz Criterion tests). The model parameters were positive and most of them statistically significant at the $5 \%$ level. The sum of $\alpha_{1}+\beta_{1}$ was less than one. Diagnostic tests on the models were applied to ensure that there were no serious misspecification problems. The

\footnotetext{
16 These tests were conducted by using ordinary least squares, regressing the logarithmic returns of the series under analysis against a constant. The ARCH-LM test is performed on the residuals of that regression. The test consists on regressing, in a second stage regression, the square residuals against constant and lagged values of the same square residuals. The square residuals are a proxy for the variance. The null hypothesis is that the errors are homoscedastic. An $F$ statistic was used in order to test the null. The test was carried out with different lags 2 to 10 . All have the same qualitative results. Only the cases for 5 lags are reported in the main text above, given the common practice in the literature for daily data, in which there could be seasonality effects or 'day of the week effects' with that frequency of the data. Thus, five trading days can take into consideration the previously mentioned situation.

17 The relevant $t$-statistics for these estimated coefficients are -4.95 and -7.61 for the IPC and -9.33 and -6.80 for the S\&P500, which clearly rejects the null hypothesis of the estimated coefficients being equal to zero at the $1 \%$ significance level.
} 
Ljung-Box statistic in the Autocorrelation Function was applied on the standardized residuals obtained from the forecast models (white noise test). This shows that these residuals are white noise by analysing the test statistic at the twelve lag, so these are i.i.d., which show no serious specification problems with the estimated models, considering that Portmanteau test.

Table 3 shows the descriptive statistics for the daily volatility and the volatility from the forecasting models for the IPC and S\&P500. As it can be observed, the means of the futures IPC series are the ones with higher values (the daily volatilities and the volatility forecasts). The distributions in that table are highly skewed and leptokurtic, indicating non-normality of the returns and the forecast estimates. This is consistent with the work of Wei and Leuthold (1998) that analyzed volatility in futures markets and had similar findings with daily futures price volatility for agricultural commodities. For energy commodities Xu et. al. (2019) found qualitatively similar results. In terms of the S\&P500, it can be observed that there is also clear evidence of time series (either for spot and futures prices) with a distribution different than the standard normal, given that the skewness and kurtosis values are different to zero and three respectively, which are the values for a standard normal distribution. In terms of comparing the IPC vs S\&P500, it can be observed that the kurtosis for the latter is relatively larger to that of the former. This is an indication that for the time period under analysis the S\&P500 had more extreme (tails) events, compared with the IPC.

\section{Results}

\subsection{Parametric Method}

Once the next-day volatility estimate is obtained, the $95 \%$ confidence intervals are created by multiplying \pm 1.96 by the forecasted conditional standard deviation (from the GARCH and TARCH model). An analysis is made about the number of times the observed IPC spot return was above that 95\% threshold (a violation or an exception). In order to analyse the accuracy of both methodologies the Kupiec test (1995) is applied. This test checks if the number of exceptions is consistent with the chosen confidence level. The null hypothesis is in favour of the model 'being accurate', by having statistically-speaking relevant number of exceptions considering the confidence level. As explained in Dowd and Blake (2006), in order to carry out the Kupiec test, only 3 inputs are needed. Using the same notation as in Dowd and Blake (2006) these are $(c)$ the confidence level chosen, $(x)$ the number of exceptions or violations and $(T)$ the total number of observations. The null hypothesis for the Kupiec test is $H_{0}: \hat{p}=p=\frac{x}{T}$, where $\hat{p}$ is the relevant exception rate (observed with the estimated model) and $p$ is the suggested failure rate according to the statistical table. This test follows a $\chi^{2}$ distribution and it has a likelihood-ratio form $(L R)$ as follows (Dowd and Blake: 2006),

$$
L R_{\text {Kupiec }}=-2 \ln \left(\frac{(1-p)^{T-x} p^{x}}{\left[1-\left(\frac{X}{T}\right)\right]^{T-x}\left(\frac{x}{T}\right)^{x}}\right)
$$

The Kupiec test, as explained by Jorion (2001) and Dowd and Blake (2006) and having one degree of freedom for the $\chi^{2}$ the critical value is 3.84 is applied. The non-rejection region 
(interpolating) for 889 observations (Kupiec: 1995) is $16<x<36$. So the GARCH model is rejecting the null hypothesis of having a correct model. The asymmetric volatility model (TARCH model) is not rejecting the relevant null hypothesis in favour of a 'correct' model. According to Equation 11 the Kupiec test statistic for the GARCH model is 6.5284, which clearly rejects the null of the 'correct' model (6.5284>3.8401). The TARCH model (asymmetric model) has a Kupiec test statistic of 0.0851, which clearly does not reject the null of the 'correct' model $(0.0851<3.8401)$. So, it is possible to conclude that for these estimations the asymmetric model is superior to the symmetric model in terms of risk management analysis.

The likelihood ratio (LR) type tests include the null in favour of the traditional nonasymmetric type models. Rejection of the null will be in favour of the asymmetric ARCH-type and models and option implied volatilities. The $n$-day ahead forecast horizon is also interpreted as the probability that the future stock market level will be within certain statistical confidence interval, i.e. the $95 \%$ confidence interval. It is then expected that these results can also give forecasts of the future (expected) U.S. and Mexican stock index level, which could also have implications for investmentdecision making. According to the results we can see the LR in favour of the asymmetric modelling.

\subsection{Bootstrapping Simulations}

The methodology to carry out the simulations was explained in Section III above. Tables 4 and 5 present the VaR for the bootstrap simulations performed in the IPC and S\&P500 futures series respectively. The numbers of $n$-days ahead considered in the simulations were 10 and 30 trading days. The simulations were done applying the $\operatorname{GARCH}(1,1), \operatorname{TARCH}(1,1)$ and an option implied volatility measures. The simulations were conducted for 10,000 replications. For each replication the lowest, highest and the average were taken from time series to separate matrices (low, average, high). In order to obtain the MCRR for the long position, the relevant observations from the low value matrix were considered. The same applies for the short position, but for that case, the matrix with the highest values were considered. This follows the logic that for long positions price decreases (low values) are risks for potential losses and for short positions price increases (high values) are risk for potential losses. It should be pointed out that Basel Accords recommend 60 days and not only 30 days ahead forecasts.

Considering the fact that the IPC spot returns have autocorrelation, it is necessary to do the bootstrap adjusting for this autocorrelated process. The procedure postulated by Politis and Romano (1994) is applied here. This is basically a method in which the autocorrelated returns are grouped into non-overlapping blocks. For this case the size of these blocks is fixed during the estimation. ${ }^{18}$ With the bootstrap the blocks are resampled. During the simulation of the IPC spot prices the returns are taken from the resample blocks. The intuition is that if the autocorrelations are negligible for a length greater than the fixed size of the block, then this 'moving block bootstrap' will estimate samples with approximately the same autocorrelation structure as the original series (Brownstone and Kazimi: 2000). Thus, with this procedure the autocorrelated process of the residuals is almost replicated and it is possible to obtain a more accurate simulated IPC spot series. In addition, that standard procedure is common practice for similar types of estimations considering sample sizes and

18 It is also possible to have random size blocks. For a more detailed explanation please refer to Politis and Romano (1994). 
statistical dynamics of the series (Mader et. al.: 2013, Shao and Tu: 2012, Kosowski et. al. 2006, Brownstone and Valleta: 2001). ${ }^{19}$

From Table 4 it can be observed that for ten trading days long and short positions (third and fourth columns) the null hypothesis is rejected for the $\operatorname{GARCH}(1,1)$ model and not rejected for the TARCH(1,1) model during the simulated period from 19/12/2019 until 30/12/2019. Not rejecting the null is in favor of the 'correct' model, so it can be observed that the asymmetric volatility model is superior to its counterpart. The expected value is $46,448.85$, which refers to the level of the IPC expected for $30 / 12 / 19$. Similar qualitative results to those of ten trading days are observed for S\&P500 series. However, for that series the GARCH(1,1) estimations do reject the null. An explanation for these results is that the adjustment of the volatility forecast for asymmetric effects show a gain, statistically speaking, compared to not having the adjustment, as it can be observed for those estimations besides the GARCH $(1,1)$. In this case the expected value for that stock index is 2,621.74 for the 30/12/19. These results are consistent with Jozef et. al. (2016) who did it for the U.S. stocks in seven sectors. We can observe that for the 30-day ahead time horizon, besides the GARCH $(1,1)$ estimations for the remaining models the null is not rejected showing that they are qualitatively similar in terms capturing the relevance between asymmetric and symmetric models. This is true for 1-day and 10-day ahead VaR estimations. For both cases we can observe gains that range from 4 to around 150 basis points of minimum capital risk requirements (VaR). However, a word of caution must be made. Clare et. al (2002) argue about the possibility of the volatility persistence in the series, that are sometimes observed in ARCH-type, estimations may overestimate the VaR. Further research for other financial assets, i.e. exchange rate, interest rates, commodity prices in addition to the possibility of expanding the present analysis to include stochastic volatility estimations as well as for different periods is encouraged. Also, it is recommended to extend the analysis to Conditional VAR (CVaR) and Expected Shortfall (ES).

\section{Conclusions}

In the present research we analyze volatility asymmetries in stock indices with superior performance and more Kupiec-accurate forecasts than those obtained through symmetric models within a Valueat-Risk (VaR) framework. We estimate three main volatility forecasts models: a backward looking ARCH-type model, a forward-looking option-implied volatility model, and VaR models with volatility asymmetries. The results show that VaR models with asymmetries provide superior estimates relative to the same model without asymmetries. The empirical case is for the Mexican Stock Index and the S\&P 500 Index daily future prices from 2016 to 2019. According to the estimated results, the

\footnotetext{
${ }^{19}$ Some part of the literature evidenced that for strongly dependent returns the use of block-bootstrapping fails. However, there is no consensus about it. Parts of the literature in which they advocate the statistical robustness of that blockbootstrapping methodology for some autocorrelated process, that are not specifically strongly dependent (See for example, Shao and Tu: 2012, Kosowski et. al. 2006, Brownstone and Valleta: 2001). The basic idea behind the latter is that there is a problem of observations in the same block being dependent in the bootstrap samples, but observations in different blocks are independent. The procedure carried out in the present research paper applies a moving block bootstrap, which is in line with that part of the literature. I am thankful to an anonymous referee for pointing out the problems of blockbootstrapping estimation.
} 
null hypothesis about ARCH-type and Option-implied asymmetric volatility being not accurate to estimate VaR was rejected in favor of modelling VaR models with volatility asymmetries. Thus, there is a statistical gain in terms of applying an asymmetrical volatility model within a VaR (Risk Management) framework. Thus, it is concluded that it is important to carry out asymmetric volatility forecasts within VaR models in order to obtain more accurate risk measures. Our findings are in line with the literature, regarding the relevance of taking into account volatility asymmetries as we show sizeable improvements when comparing estimates of symmetric volatility VaR models to those obtained in both backward and forward- looking forecasts models. The referred gains range from 4 to around 150 basis points of minimum capital risk requirements (VaR). It is documented the relevance of taking into account volatility asymmetries for both broad volatility estimation methodologies, backward- vs. forward-looking.

\section{References}

[1] Benavides, G. (2006). Volatility Forecasts for the Mexican Peso - U.S. Dollar Exchange Rate: An Empirical Analysis of GARCH, Option Implied and Composite Forecast Models. Series de Documentos de Investigación del Banco de México, No. 2006-04.

[2] Benavides, G. (2009). Price Volatility Forecasts for Agricultural Commodities: An Application of Historical Volatility Models, Option Implieds and Composite Approaches for Futures Prices of Corn and Wheat. Journal of Management, Finance and Economics. Vol. 3, Issue 2, pp. 40-59. https://doi.org/10.2139/ssrn.611062

[3] Benavides, G. and Snowden P. N. (2006). Futures for Farmers: Hedging Participation and the Mexican Corn Scheme. Journal of Development Studies. Vol. 42, No. 4, pp. 698 - 712. https://doi.org/10.1080/00220380600682330

[4] Bollerslev, T. P. (1986). Generalized Autoregressive Conditional Heteroscedasticity. Journal of Econometrics. Vol. 31, pp. 307-327.

[5] Bollerslev, T. P., Chou, R. Y. and Kroner, K. F. (1992). ARCH Modeling in Finance: A Review of the Theory and Empirical Evidence. Journal of Econometrics Vol. 52, pp.5-59. https://doi.org/10.1016/03044076(92)90064-x

[6] Bollerslev, T. and Wooldridge, J. M. (1992) "Quasi-Maximum Likelihood Estimation and Inference in Dynamic Models with Time Varying Covariances," Econometric Reviews, Vol. 11, pp. 143-172.

[7] Brooks, C. (2013). Introductory Econometrics for Finance. Cambridge University Press.

[8] Brownstone, D. and Kazimi, C. (2000). Applying the Bootstrap, Dept. of Economics, Working Paper, University of California, Irvine.

[9] Brownstone, D. and Valletta, R. (2001). The Bootstrap and Multiple Imputations: Harnessing Increased Computing Power for Improved Statistical Tests. Journal of Economic Perspectives, Vol. 15, Issue 4, pp. 129-141. https://doi.org/10.1257/jep.15.4.129

[10] Dowd, K. (1998). Beyond Value at Risk: The New Science of Risk Management. Chichester and New York: Wiley and Sons.

[11] Dowd, K. and Blake, D. (2006). After VaR: The Theory, Estimation, and Insurance Applications of Quantile-Based Risk Measures. Journal of Risk and Insurance. Vol. 73, Issue 2, pp. 193-229. https://doi.org/10.1111/j.1539-6975.2006.00171.x

[12] Efron, B. (1982). The Jacknife, the Bootstrap, and other Resampling Plans. Society for Industrial and Applied Mathematics. Philadelphia, PA, USA. 
REMEF (The Mexican Journal of Economics and Finance)

Asymmetric Volatility Relevance in Risk Management: An Empirical Analysis using Stock Index Futures

[13] Engle, R. F. (1982) Autoregressive Conditional Heteroskedasticity with Estimates of the Variance of U.K. Inflation, Econometrica. Vol. 50, pp. 987-1008. https://doi.org/10.2307/1912773

[14] Engle, R. F. (2002). Dynamic Conditional Correlation - A Simple Class of Multivariate GARCH Models. Journal of Business \& Economic Statistics. Vol. 20, No. 3, pp. 339-350.

[15] Engle, R. F. (2003). Risk and Volatility: Econometrics Models and Financial Practice. Economics Nobel Prize Lecture. New York University, Department of Finance, New York, USA. December.

[16] Fink, R. E. and Feduniak, R. B. (1988). Futures Trading: Concepts and Strategies. NYIF Corp.

[17] Giot, P. (2005). Implied Volatility Indexes and Daily Value at Risk Models. Journal of Derivatives. Vol. 12. pp.54-64. https://doi.org/10.3905/jod.2005.517186

[18] Glosten, L. R., Jaganathan, R. and Runkle, D. (1993). On the Relation between the Expected Value and the Volatility of the Normal Excess Return on Stocks. Journal of Finance. Vol. 48, pp. 1779-1801. https://doi.org/10.21034/sr.157

[19] Hsieh, D. A. (1993). Implications of Nonlinear Dynamics for Financial Risk Management. Journal of Financial and Quantitative Analysis. Vol. 28. pp. 41-64.

[20] Hull, J. 2019. Options, Futures and Other Derivatives. 10 ${ }^{\text {th }}$. Edition. Prentice Hall.

[21] Johnson, N. L. (1949) Systems of Frequency Curves Generated by Methods of Translations. Biometrika. pp. 149-175.

[22] Jozef Baruník, Evžen Kočenda, Lukáš Vácha. (2016) Asymmetric connectedness on the U.S. stock market: Bad and good volatility spillovers. Journal of Financial Markets. Volume 27, pp 55-78.

[23] Jorion, P. (2001). Value at Risk: The Benchmark for Managing Market Risk. McGraw-Hill.

[24] J.P. Morgan/Reuters Risk Metrics Technical Document. (1996). Available in the following Web page: http://www.riskmetrics.com/rmcovv.html

[25] Kosowski, R., Timmermann, A., Wermers, R. and White, H. (2006). Can Mutual Fund 'Stars' Really Pick Stocks? New Evidence from a Bootstrap Analysis. The Journal of Finance. Vol. 61, Issue 6, pp. 25512596. https://doi.org/10.1111/j.1540-6261.2006.01015.x

[26] Kupiec, P. H. (1995). Techniques for Verifying the Accuracy of Risk Measurement Models. Finance and Economics Discussion Series 95-24. Board of Governors of the Federal Reserve System. USA.

[27] Mader, M., Mader, W., Sommerlade, L., Timmer, J. and Schelter, B. (2013). Block-bootstrapping for Noisy Data, Journal of Neuroscience Methods, Vol. 219, Issue 2, pp 285-291.

[28] Manfredo, M. Leuthold, R. M. and Irwin, S. H. (2001). Forecasting Cash Price Volatility of Fed Cattle, Feeder Cattle and Corn: Time Series, Implied Volatility and Composite Approaches. Journal of Agricultural and Applied Economics. Vol. 33. Issue 3, pp. 523-538.

[29] Park, D. W. and Tomek, W. G. (1989). An Appraisal of Composite Forecasting Methods. North Central Journal of Agricultural Economics. Vol. 10, pp.1-11.

[30] Politis, D.M. and Romano, J. P. (1994). The Stationary Bootstrap. Journal of the American Statistical Association. Vol. 89. No. 428, pp. 1303-1313.

[31] Pong, S., Shackleton, M., Taylor, S. and Xu, X. (2003) Forecasting Currency Volatility: A Comparison of Implied Volatilities and AR(FI)MA models Journal of Banking and Finance. Vol. 28, Issue 10, pp. 25412563 ,

[32] Schroeder, T. C., Albright, M. L., Langemeier, M. R. and Mintert, J. (1993). Factors Affecting Cattle Feeding Profitability. Journal of the American Society of Farm Managers and Rural Appraisers. Vol. 57, pp. 48-54.

[33] Shao, J. and Tu, D. (2012) The Jackknife and Bootstrap. Springer Finance Publishers.

[34] Taylor, S. J. (1986). The Behaviour of Futures Prices Overtime. Applied Economics, Vol. 17, Issue 4, pp. 713-734. 
[35] Wei, A. and Leuthold, R. M. (1998). Long Agricultural Futures Prices: ARCH, Long Memory, or Chaos Processes. OFOR Paper Number 98-03. University of Illinois at Urbana - Champaign. Available at SSRN: https://ssrn.com/abstract=126951

[36] or http://dx.doi.org/10.2139/ssrn.126951

[37] Weiju Xu, Feng Ma, Wang Chen, Bing Zhang. (2019) Asymmetric volatility spillovers between oil and stock markets: Evidence from China and the United States. Energy Economics, Volume 80, 2019, pp. 310-320, ISSN 0140-9883.

[38] Zakoïan, J. M. (1994). Threshold Heteroskedastic Models. Journal of Economic Dynamics and Control. Vol. 18, pp. 931-944. https://doi.org/10.1016/0165-1889(94)90039-6

[39] Zivot, E. (2009) Practical Issues in the Analysis of Univariate GARCH Models. In: Mikosch T., Kreiß JP., Davis R., Andersen T. (eds) Handbook of Financial Time Series. Springer, Berlin, Heidelberg.

\section{Appendix}

Table 1. Volatility Estimates (Variance Equation) of the Daily Spot and Futures Prices of the IPC

\begin{tabular}{|c|c|c|c|c|}
\hline GARCH(1, 1) & Spot & Futures & $\begin{array}{c}\text { TARCH(1,1) } \\
\text { Spot }\end{array}$ & Futures \\
\hline$a_{0}$ & $\begin{array}{c}1.49 \times 10^{-4} \\
\left(3.06 \times 10^{-4}\right)\end{array}$ & $\begin{array}{c}6.13 \times 10^{-6} \\
\left(2.25 \times 10^{-6}\right)^{* *}\end{array}$ & $\begin{array}{c}1.25 \times 10^{-5} \\
\left(3.75 \times 10^{-6}\right)^{* * *}\end{array}$ & $\begin{array}{c}5.01 \times 10^{-6} \\
\left(1.75 \times 10^{-6}\right)^{* *}\end{array}$ \\
\hline$a_{1}$ & 0.1899 & 0.1322 & 0.2097 \\
$\left(4.42 \times 10^{-2}\right)^{* * *}$ & $\left(3.28 \times 10^{-2}\right)^{* * *}$ & $\left(6.09 \times 10^{-2}\right)^{* * *}$ & $\begin{array}{c}0.0689 \\
\left(2.76 \times 10^{-2}\right)^{* *}\end{array}$ \\
\hline$b_{1}$ & 0.5802 & 0.7731 & 0.5830 & 0.823 \\
$(0.0915)^{*}$ & $(0.0398)^{* *}$ & $0.0957)^{* *}$ & $(0.0379)^{* *}$ \\
\hline$\delta$ & $N / A$ & $N / A$ & 0.00045 & 0.1194 \\
$(0.0007)^{* *}$ & $(0.0415)^{* *}$ \\
\hline$L$ & $1,802.52$ & $1,686.40$ & $1,806.95$ & $1,690.67$ \\
\hline$Q(12)$ & 18.26 & 12.08 & 19.18 & 14.82 \\
\hline$Q^{2}(12)$ & 14.87 & 12.83 & 13.69 & 48.65 \\
\hline$N$ & 889 & 889 & 889 & 889 \\
\hline
\end{tabular}

This table reports parameter values of the GARCH $(1,1)$ and TARCH(1,1) models. Standard errors are shown in brackets. $L$ represents the $\log$ likelihood of the estimation. The rows showing $Q(12)$ and $Q^{2}(12)$ are the LjungBox statistic for standardized residuals and standardized residuals squared respectively, which has a $c^{2}$ distribution with 5 degrees of freedom. The critical value is 21.02 at the $5 \%$ level. $N$ represents the sample size. The sample size consists of daily data from June 2016 to December 2019. Source: Bloomberg and Banco de México. 
Table 2. Volatility Estimates (Variance Equation) of the Daily Spot and Futures Prices of the S\&P500

\begin{tabular}{|c|c|c|c|c|}
\hline GARCH(1, 1) & Spot & Futures & $\begin{array}{c}\text { TARCH(1,1) } \\
\text { Spot }\end{array}$ & Futures \\
\hline$a_{0}$ & $\begin{array}{c}4.58 \times 10^{-6} \\
\left(7.93 \times 10^{-4}\right)^{* * *}\end{array}$ & $\begin{array}{c}4.38 \times 10^{-6} \\
\left(5.75 \times 10^{-7}\right)^{* *}\end{array}$ & $\begin{array}{c}4.29 \times 10^{-6} \\
\left(6.19 \times 10^{-7}\right)^{* * *}\end{array}$ & $\begin{array}{c}3.65 \times 10^{-6} \\
\left(4.43 \times 10^{-7}\right)^{* * *}\end{array}$ \\
\hline$a_{1}$ & 0.1751 & 0.2470 \\
$(0.0288)^{*}$ & $0.0280)^{* *}$ & -0.0235 & $0.00276)$ \\
$(0.7356$ & $(0.0337)^{* *}$ & $\begin{array}{c}0.7589 \\
(0.0369)^{* *}\end{array}$ & $\begin{array}{c}0.7314 \\
(0.0255)^{* *}\end{array}$ \\
\hline$b_{1}$ & $(0.0389)^{*}$ & $N / A$ & 0.3184 & 0.1301 \\
$(0.042)^{* *}$ & $(0.0495)^{* *}$ \\
\hline$\delta$ & $N / A$ & $1,912.22$ & $1,919.93$ & $1,919.51$ \\
\hline$Q(12)$ & $1,877.20$ & 8.613 & 7.23 & 7.73 \\
\hline$Q^{2}(12)$ & 8.23 & 3.83 & 2.45 & 3.433 \\
\hline$N$ & 3.87 & 889 & 889 & 889 \\
\hline
\end{tabular}

This table reports parameter values of the GARCH(1,1) and TARCH(1,1) models. Standard errors are shown in brackets. $L$ represents the log likelihood of the estimation. The rows showing $Q(12)$ and $Q^{2}(12)$ are the LjungBox statistic for standardized residuals and standardized residuals squared respectively, which has a $c^{2}$ distribution with 5 degrees of freedom. The critical value is 21.02 at the $5 \%$ level. $N$ represents the sample size. The sample size consists of daily data from June 2016 to December 2019. Source: Bloomberg, Banco de México, Fred Database.

Table 3. Descriptive Statistics for the Daily Volatility of the Spot and Futures IPC the Forecasting Models

\begin{tabular}{|c|c|c|c|c|c|}
\hline $\begin{array}{l}\text { Model/Series } \\
\text { IPC/S\&P500 }\end{array}$ & Mean & Std. Deviation & Skewness & $\begin{array}{c}\text { Kurtosi } \\
\text { s }\end{array}$ & $N$ \\
\hline Spot daily & $5.54 \times 10^{-3}$ & $4.99 \times 10^{-3}$ & 2.3350 & 14.33 & 889 \\
\hline \multicolumn{6}{|c|}{ volatility series } \\
\hline & $4.34 \times 10^{-3}$ & $1.28 \times 10^{-3}$ & 2.7614 & 14.75 & 889 \\
\hline Futures daily & $6.88 \times 10^{-3}$ & $6.32 \times 10^{-3}$ & 2.1365 & 10.15 & 889 \\
\hline \multicolumn{6}{|c|}{ volatility series } \\
\hline & $4.53 \times 10^{-3}$ & $5.65 \times 10^{-3}$ & 3.4085 & 23.36 & 889 \\
\hline GARCH(1,1) & $5.44 \times 10^{-5}$ & $3.79 \times 10^{-5}$ & 6.9702 & 79.36 & 889 \\
\hline $\begin{array}{l}\text { model for the } \\
\text { spot series }\end{array}$ & $4.36 \times 10^{-5}$ & $3.69 \times 10^{-5}$ & 6.6691 & 79.23 & 889 \\
\hline GARCH $(1,1)$ & $9.11 \times 10^{-5}$ & $5.87 \times 10^{-14}$ & 2.3384 & 9.15 & 889 \\
\hline $\begin{array}{l}\text { model for the } \\
\text { futures series }\end{array}$ & $9.13 \times 10^{-5}$ & $5.29 \times 10^{-14}$ & 2.3719 & 11.39 & 889 \\
\hline TARCH $(1,1)$ & $5.57 \times 10^{-5}$ & $3.89 \times 10^{-5}$ & 6.9191 & 79.87 & 889 \\
\hline
\end{tabular}




\begin{tabular}{|c|c|c|c|c|c|}
\hline $\begin{array}{c}\text { model for the } \\
\text { spot series }\end{array}$ & $4.92 \times 10^{-5}$ & $2.24 \times 10^{-5}$ & 4.7726 & 31.63 & 889 \\
\hline TARCH(1,1) & $9.15 \times 10^{-5}$ & $5.86 \times 10^{-5}$ & 2.4319 & 11.98 & 889 \\
\hline $\begin{array}{c}\text { model for the } \\
\text { futures series }\end{array}$ & $5.18 \times 10^{-5}$ & $2.36 \times 10^{-5}$ & 5.7714 & 46.84 & 889 \\
\hline
\end{tabular}

This table reports the descriptive statistics of the daily volatility and the volatility forecasting models for the daily IPC and S\&P500 spot and futures returns. The sample includes 889 daily observations from $19^{\text {th }}$ June 2016 to $30^{\text {th }}$ December 2019. $N=$ Number of observations. Source: Bloomberg, Banco de México, Fred Database.

Table 4. VaR for The IPC Futures Portfolio Obtained with Bootstrapping Simulations

\begin{tabular}{|c|c|c|c|c|}
\hline Model & $\begin{array}{c}\text { VaR t-day } \\
\text { horizon (trading } \\
\text { days) }\end{array}$ & $\begin{array}{c}\text { Minimum } \\
\text { capital risk } \\
\text { requirement } \\
\text { long position }\end{array}$ & $\begin{array}{l}\text { Minimum } \\
\text { capital risk } \\
\text { requirement } \\
\text { short position }\end{array}$ & $\begin{array}{l}\text { Kupiec-test } \\
\text { outcome }\end{array}$ \\
\hline $\begin{array}{l}\text { GARCH(1,1) } \\
\text { TARCH }(1,1)\end{array}$ & $\begin{array}{l}10 \text { trading days } \\
\text { (from } \\
19 / 12 / 2019 \\
\text { until } \\
30 / 12 / 2019 \text { ). }\end{array}$ & $8.23 \%$ & $3.74 \%$ & $\begin{array}{l}\text { Reject the null } \\
\text { Do not reject } \\
\text { the null }\end{array}$ \\
\hline GARCH(1,1) & \multirow{3}{*}{$\begin{array}{l}30 \text { trading days } \\
\text { (from } \\
30 / 11 / 2019 \\
\text { until } \\
30 / 12 / 2019 \text { ). }\end{array}$} & $15.85 \%$ & $5.34 \%$ & \multirow{3}{*}{$\begin{array}{l}\text { Do not reject } \\
\text { the null } \\
\text { Do not reject } \\
\text { the null } \\
\text { Do not reject } \\
\text { the null }\end{array}$} \\
\hline $\operatorname{TARCH}(1,1)$ & & $15.24 \%$ & $5.47 \%$ & \\
\hline $\begin{array}{l}\text { Implied } \\
\text { volatility } \\
\text { (VIMEX) }\end{array}$ & & $9.83 \%$ & $4.96 \%$ & \\
\hline
\end{tabular}

This table presents the results of the bootstrap simulations. 10,000 replications were applied to simulate the IPC price. The time horizons are 10 and 30 trading days. IPC futures prices are used for this table. The models applied are GARCH(1,1), TARCH(1,1) and the Implied Volatility (VIMEX). The Kupiec-test outcome refers to the statistical test (result) as explained in Kupiec (1995). The sample size is 889 observations from $17^{\text {th }}$ June 2016 to $30^{\text {th }}$ December 2019. Source: Bloomberg and Banco de México. 
Table 5. VaR for the S\&P500 Futures Portfolio Obtained with Bootstrapping Simulations

\begin{tabular}{|c|c|c|c|c|}
\hline Model & $\begin{array}{c}\text { VaR } t \text {-day } \\
\text { horizon (trading } \\
\text { days) }\end{array}$ & $\begin{array}{c}\text { Minimum } \\
\text { capital risk } \\
\text { requirement } \\
\text { long position }\end{array}$ & $\begin{array}{c}\text { Minimum } \\
\text { capital risk } \\
\text { requirement } \\
\text { short position }\end{array}$ & $\begin{array}{c}\text { Kupiec-test } \\
\text { outcome }\end{array}$ \\
\hline $\begin{array}{l}\operatorname{GARCH}(1,1) \\
\operatorname{TARCH}(1,1)\end{array}$ & $\begin{array}{l}10 \text { trading days } \\
\text { (from } \\
19 / 12 / 2019 \\
\text { until } \\
30 / 12 / 2019 \text { ). }\end{array}$ & $6.25 \%$ & $11.35 \%$ & $\begin{array}{l}\text { Reject the } \\
\text { null } \\
\text { Do not } \\
\text { reject the } \\
\text { null }\end{array}$ \\
\hline $\operatorname{GARCH}(1,1)$ & \multirow{3}{*}{$\begin{array}{l}30 \text { trading days } \\
\text { (from } \\
30 / 11 / 2019 \\
\text { until } \\
30 / 12 / 2019 \text { ). }\end{array}$} & $11.99 \%$ & $12.84 \%$ & $\begin{array}{l}\text { Reject the } \\
\text { null }\end{array}$ \\
\hline $\operatorname{TARCH}(1,1)$ & & $10.26 \%$ & $13.51 \%$ & $\frac{\text { Do not }}{\text { reject the }}$ \\
\hline $\begin{array}{l}\text { Implied } \\
\text { volatility (VIX) }\end{array}$ & & $10.43 \%$ & $11.44 \%$ & $\begin{array}{l}\text { null } \\
\text { Do not } \\
\text { reject the } \\
\text { null }\end{array}$ \\
\hline
\end{tabular}

This table presents the results of the bootstrap simulations. 10,000 replications were applied to simulate the S\&P500 price. The time horizons are 10 and 30 trading days. S\&P500 futures prices are used for this table. The models applied are GARCH(1,1), TARCH(1,1) and the Implied Volatility (VIX). The Kupiec test outcome refers to the statistical test (result) as explained in Kupiec (1995). The sample size is 889 observations from $17^{\text {th }}$ June 2016 to $30^{\text {th }}$ December 2019. Source: Bloomberg and Banco de México. 